Article

\title{
Optimized Production of a Redox Metabolite (pyocyanin) by Pseudomonas aeruginosa NEJ01R Using a Maize By-Product
}

\author{
Francisco Javier Bacame-Valenzuela ${ }^{1,2}{ }^{\mathbb{D}}$, Jesús Alberto Pérez-Garcia ${ }^{1}$, \\ Mayra Leticia Figueroa-Magallón ${ }^{1}$, Fabricio Espejel-Ayala ${ }^{1}$, Luis Antonio Ortiz-Frade ${ }^{1}$ \\ and Yolanda Reyes-Vidal 1,2,*(D) \\ 1 Centro de Investigación y Desarrollo Tecnológico en Electroquímica (CIDETEQ), \\ Parque Tecnológico Querétaro s/n, Sanfandila, Pedro Escobedo, Querétaro C.P. 76703, Mexico; \\ fbacame@cideteq.mx (F.J.B.-V.); jgarcia@cideteq.mx (J.A.P.-G.); mfigueroa@cideteq.mx (M.L.F.-M.); \\ fespejel@cideteq.mx (F.E.-A.); lortiz@cideteq.mx (L.A.O.-F.) \\ 2 Consejo Nacional de Ciencia y Tecnología (CONACYT) - Centro de Investigación y Desarrollo Tecnológico \\ en Electroquímica (CIDETEQ), Parque Tecnológico Querétaro s/n, Sanfandila, Pedro Escobedo, \\ Querétaro C.P. 76703, Mexico \\ * Correspondence: mreyes@cideteq.mx
}

Received: 13 August 2020; Accepted: 24 September 2020; Published: 10 October 2020

\begin{abstract}
Pseudomonas aeruginosa metabolizes pyocyanin, a redox molecule related to diverse biological activities. Culture conditions for the production of pyocyanin in a defined medium were optimized using a statistical design and response surface methodology. The obtained conditions were replicated using as substrate an alkaline residual liquid of cooked maize and its by-products. The untreated effluent (raw nejayote, RN) was processed to obtain a fraction without insoluble solids (clarified fraction, CL), then separated by a $30 \mathrm{kDa}$ membrane where two fractions, namely, retentate (RE) and filtered (FI), were obtained. Optimal conditions in the defined medium were $29.6{ }^{\circ} \mathrm{C}, 223.7 \mathrm{rpm}$ and $\mathrm{pH}=6.92$, which produced $2.21 \mu \mathrm{g} \mathrm{mL}^{-1}$ of pyocyanin, and by using the wastewater, it was possible to obtain $3.25 \mu \mathrm{g} \mathrm{mL}^{-1}$ of pyocyanin in the retentate fraction at $40 \mathrm{~h}$. The retentate fraction presented the highest concentration of total solids related to the maximum concentration of pyocyanin (PYO) obtained. The pyocyanin redox behavior was analyzed using electrochemical techniques. In this way, valorization of lime-cooked maize wastewater (nejayote) used as a substrate was demonstrated in the production of a value-added compound, such as pyocyanin, a redox metabolite of Pseudomonas aeruginosa NEJ01R.
\end{abstract}

Keywords: pyocyanin; maize industry wastewater; Pseudomonas aeruginosa NEJ01R; redox metabolite; optimization; response surface analysis; bioproduction; valorization; electrochemical analysis

\section{Introduction}

Microorganisms can produce a large variety of extracellular compounds with different biological activities. Currently, there are more than 50,000 natural products used as drugs that are derived from microorganisms, mostly isolated from soil samples [1]. The genus Pseudomonas, Gram-negative aerobic Gammaproteobacteria belonging to the family Pseudomonadaceae, is known to produce a series of extracellular redox metabolites of the phenazine group. Species of the genus Pseudomonas are characterized by their metabolic versatility, giving them great relevance in environmental recycling processes, degrading a wide range of simple and complex organic compounds [2-4]. It has been demonstrated that Pseudomonas aeruginosa produces 5-methylphenazine-1-one or pyocyanin (PYO), a water-soluble blue-green pigment with a redox potential similar to menaquinone [5]. 
PYO is a biomolecule that participates in the quorum-sensing process of P. aeruginosa. This bacterial mechanism is used to coordinate population density, as well as for the regulation of gene expression and biofilm formation [6,7]. Pseudomonas integrates a bacterial strategy through PYO molecules for the inhibition of fungal phytopathogens of agricultural crops and cytostatic activity against cancer cell lines [8]. The antagonistic effect of the compounds derived from phenazines is associated with their redox behavior. Therefore, it is believed that many capabilities of PYO and other phenazine derivatives, in a variety of eukaryotic hosts and bacteria, are the result of oxidative activity or inactivation of important proteins in response to oxidative stress [9].

The redox process for PYO was studied through cyclic and square wave voltammetries. PYO and other redox metabolites included in the secretome of $P$. aeruginosa could be used as electrochemical biomarkers to detect its presence in a bacterial culture supernatant [10]. Furthermore, P. aeruginosa is considered an electrogenic microorganism and is used in bioelectrochemical systems for electrical energy production, carried out by direct electron transfer (through cytochromes in outer membrane or bacteria pili) and indirect electron transfer (through secondary metabolites excreted by bacteria). In this case, PYO of P. aeruginosa is the extracellular metabolite that facilitates electronic transfer between microorganism and electrode due to its reversible redox properties [11]. However, one disadvantage of PYO is its market cost since $5 \mathrm{mg}$ (purity $>98 \%$, HPLC grade) has a cost of 60-97 USD according to different suppliers [12-15]. Therefore, optimized processes must be developed that allow the metabolite to be obtained at high concentrations through operations less harmful to the environment, such as green chemistry, to extend the use of PYO.

An attractive approach is to use residues as substrates in bioprocesses to obtain value-added molecules. In this way, PYO production by submerged fermentation of P. aeruginosa has been carried out in glycerol (residues of biodiesel production) and a defined medium supplemented with a broad variety of raw materials $[5,16,17]$. One of the options to achieve this goal is the use of wastewaters as a carbon source, which could be considered toxic for the environment, but the use in culture media is an alternative that reduces its polluting and harmful potential, as well as its valorization.

Currently, among the agro-food-processing industrial effluents considered as environmental pollutants are by-products generated in the maize (Zea mays) cooking process. This traditional process is known as "nixtamalization" and includes boiling corn grains in a saturated solution of calcium hydroxide $(0.5-2 \%)$ at $90{ }^{\circ} \mathrm{C}$ for $40 \mathrm{~min}$; after this process, the corn grains are steeped for $12 \mathrm{~h}$, then drained, and the resulting liquid is commonly known as nejayote [18,19]. Cooked maize grains (nixtamal) are used for the production of masa, tortillas and derived products in Mexico, Southern United States, Central and South America, Asia and parts of Europe. In Mexico, it is estimated that 14.4 million $\mathrm{m}^{3}$ of nejayote is produced annually [20]. This wastewater is considered as a pollutant due to its contents extracted during the process: $0.5-14.5 \%$ of the corn's weight goes to the effluent, which has a $\mathrm{pH}$ of 12 [18]. Various compounds and some phytochemicals associated with the cell wall of corn grains are released by alkaline hydrolysis and are related to parameters such as total organic carbon (TOC; 2700-59,000 mg L ${ }^{-1}$ ), biochemical oxygen demand (BOD; $2.69 \mathrm{mg} \mathrm{O}_{2} \mathrm{~L}^{-1}$ ) and chemical oxygen demand (COD; 7500-40,000 $\mathrm{mg} \mathrm{L}^{-1}$ ) [21-24]. Some of these parameters also indicate that the effluent has a high content of organic material (reducing and total sugars), which together with other compounds (protein, fiber, fat, calcium, arabinoxylans and polyphenols) define its content of nutrients (carbon source) and inorganic compounds, potentially applicable for biotechnological applications [25-29].

Likewise, this wastewater can be used as a raw substrate by microorganisms to obtain bioproducts. Aspergillus oryzae and different species of Lactobacillus produce a protease and bacteriocins, respectively, using nejayote as a substrate [30,31]. In other studies, two native isolated bacteria (Bacillus flexus) were used to biosynthesize amylases, xylanases, proteases and phenolic acid esterase [32]. Recently, Bacillus megaterium (a native nejayote strain) was able to transform ferulic acid present in the effluent into 4-vinylguaiacol [33]. Moreover, nejayote in combination with other residual effluents such as vinasse (a waste from tequila production) and swine wastewater allow for obtaining bioenergy or can used for 
the growth of microalgae [24,34]. Thus, it is clear that components of nejayote can be exploited for the production of different biotechnological products. Therefore, the objective of this work was to valorize lime-cooked maize wastewater as a culture medium to produce a redox metabolite using P. aeruginosa NEJ01R and to develop optimized culture conditions (temperature, $\mathrm{pH}$ and agitatio(n) in a defined culture medium by response surface methodology.

\section{Materials and Methods}

\subsection{Microorganism}

Bacteria were isolated from lime-cooked maize wastewater collected from a local mill situated in Pedro Escobedo, Querétaro (Mexico). Samples (1 mL) of nejayote at $\mathrm{pH} 11$ (without other treatments) were plated on LB agar and incubated at $30{ }^{\circ} \mathrm{C}$ for $48 \mathrm{~h}$. The composition of the LB agar was $\mathrm{g} \mathrm{L}^{-1}$ ) casein peptone (10), yeast extract (5), sodium chloride (0.5) and bacteriology agar (15). Single colonies with different morphologies were plated again in LB agar. Three colonies (NEJ01R, NEJR5 and NEJ03R) were selected because a green coloration was observed in plates. NEJ01R was used in this study because it showed pigment production in $24 \mathrm{~h}$ and growth in different substrates [16]. The strain NEJ01R was characterized using Gram stain (-) and the biochemical test API 20E (bioMérieux) as Pseudomonas aeruginosa. Genomic DNA was isolated from pure bacterial colonies using methodology described by [35]. A nucleotide sequence analysis (16 rRNA gene) was performed at Laboratorio Nacional de Biotecnología Agrícola, Médica y Ambiental (LANBAMA) (San Luis Potosi, México). The resulting rRNA sequences were submitted to the non-redundant nucleotide database at GenBank using the Basic Local Alignment Search Tool (BLAST) program to determine its identity. P. aeruginosa NEJ01R sequence showed $92.30 \%$ similarity to P. aeruginosa ACR20 with the NCBI Accession Number CP058333.1. The strain was stored on Luria-Bertani agar (LB) at $4{ }^{\circ} \mathrm{C}$.

\subsection{Statistical Design and Optimization by Response Surface}

To optimize conditions of culture for biomass production and PYO generation in the defined culture medium, a central compound design was chosen with three experimental factors: temperature, $\mathrm{pH}$ and agitation speed. Design analysis and subsequent analysis of the experimental data were recorded in Statgraphics Technologies, Inc. (The Plains, Virginia, USA, version 15.0). Table S1 shows the design matrix. Experimental factors evaluated were obtained from preliminary experimental results. Nineteen experiments were achieved because five central points were selected to complete the lack-of-fit test. Biomass and PYO were the response variables and were measured randomly at $48 \mathrm{~h}$, by duplication. The following equation shows the number of experiments achieved:

$$
N=2^{k}+2 k+c p
$$

where $N$ is the number of experiments, $k$ is the number of experimental factors and $c p$ denotes central points. To assure the rotatability and orthogonality in the experimental design, $\alpha$ was chosen with the next equation:

$$
\alpha=\left(\frac{(F x N)^{1 / 2}-F}{2}\right)^{1 / 2}
$$

where $F=2 k$. An analysis of variance (ANOVA) was performed to inspect the response surface model. The fitted polynomial equation was then expressed in the form of three-dimensional response surface plots to show the relationship among the responses and the experimental levels of each independent variable.

\subsection{Culture Conditions}

The inoculum was obtained from a liquid culture using LB broth. The composition of the LB broth was $\left(\mathrm{g} \mathrm{L}^{-1}\right)$ casein peptone (10), yeast extract (5) and sodium chloride (0.5). The liquid culture 
(50 mL in $250 \mathrm{~mL}$ Erlenmeyer flasks) was inoculated with a single fresh colony of P. aeruginosa NEJ01R (LB agar, $30^{\circ} \mathrm{C}$, for $24 \mathrm{~h}$ ). The inoculated LB broth was incubated at $150 \mathrm{rpm}, 30^{\circ} \mathrm{C}$, for $24 \mathrm{~h}$.

All experimental units (EUs) generated by statistical design were made in $250 \mathrm{~mL}$ Erlenmeyer flasks with $50 \mathrm{~mL}$ of LB broth (defined medium, LB) and sterilized in an autoclave at $121^{\circ} \mathrm{C}$ for $15 \mathrm{~min}$. After this, each EU was inoculated with $1 \mathrm{~mL}$ of an inoculum culture. The EUs were incubated for $48 \mathrm{~h}$ using different combinations of conditions ( $\mathrm{pH}$, temperature and agitation) established by the statistical design.

\subsection{Biomass Determination}

The biomass was determined by the dry weight method. Aluminum dishes were pre-dried to constant weight in a drying oven $\left(100{ }^{\circ} \mathrm{C}\right.$, for $\left.1 \mathrm{~h}\right)$. Later, they were allowed to cool in a desiccator, and then their initial weight was recorded. After $48 \mathrm{~h}$ of incubation, cultures were centrifuged at $6600 \times \mathrm{g}$ for $10 \mathrm{~min}$. The supernatant was decanted, and the formed pellets were transferred to an aluminum dish and were placed in a drying oven at $100{ }^{\circ} \mathrm{C}$ for $1 \mathrm{~h}$. Finally, the dishes were placed in a desiccator, and their final weight was measured. The biomass concentration was determined by the weight difference and reported in $\mathrm{g} \mathrm{L}^{-1}$.

\subsection{PYO Determination}

The decanted supernatants were used to quantify PYO by a liquid-liquid extraction method. Equal volumes of supernatant and chloroform $(3 \mathrm{~mL})$ were added and vigorously vortexed. The organic phase (blue) was separated, and a similar volume of $0.2 \mathrm{~N} \mathrm{HCl}$ was added. The mix was vigorously stirred in a vortex, and the aqueous phase (red) was separated to measure it in a UV-Vis spectrophotometer (Genesys ${ }^{\mathrm{TM}} 10 \mathrm{~S}$, Thermo Scientific, WI, USA) at $520 \mathrm{~nm}$. The absorbance obtained was multiplied by the factor 17.1 to obtain $\mu \mathrm{g} \mathrm{mL} \mathrm{m}^{-1}$ of PYO [5].

\subsection{Microbial Growth Kinetics and PYO Production}

The kinetics of microbial growth were determined in cultures of $P$. aeruginosa NEJ01R under conditions optimized for growth and PYO production according to surface response. Samples were taken every two hours for $48 \mathrm{~h}$ of culture incubation. Serial dilutions (up to $10^{-8}$ ) were made in $0.1 \mathrm{mM}$ phosphate buffer ( $\mathrm{pH}$ 7.0) for each sample. One milliliter of the dilutions was added on Petri dishes with agar standard methods and incubated $\left(30^{\circ} \mathrm{C}\right)$. After $24 \mathrm{~h}$, a bacterial count $\left(\mathrm{CFU} \mathrm{mL}{ }^{-1}\right)$ was performed. In addition to bacterial count $\left(\mathrm{CFU} \mathrm{mL}{ }^{-1}\right)$, the determination of $\mathrm{PYO}$ was made following the methodology described in Section 2.5 [5].

\subsection{Valorization of Maize Wastewater}

The wastewater was used as a culture medium (raw nejayote, $\mathrm{RN}$ ) without treatment under the conditions (composition and $\mathrm{pH}$ ) used in a traditional process. Afterward, $\mathrm{RN}$ was processed using the methodology reported by [25] employing a flocculating agent and $\mathrm{pH}$ adjustment (7.2). The fraction obtained was labeled as clarified fraction (CL). The CL fraction was filtered using a Pellicon ${ }^{\circledR}$ system (30 kDa Biomax Mini polyethersulfone cassette, Merck Millipore, MA, USA). After this ultrafiltration process, the CL fraction was divided into retentate fraction (RE) and filtered fraction (FI). Fifty milliliters of RN and each fraction (CL, RE and FI) in $250 \mathrm{~mL}$ Erlenmeyer flasks was inoculated with $1 \mathrm{~mL}$ of an inoculum culture of $P$. aeruginosa NEJ01R. Submerged fermentations were incubated for $48 \mathrm{~h}$ using operational conditions $(\mathrm{pH}$, temperature and agitation) established as optimal by the statistical design. All experiments were performed in triplicate.

\subsection{Characterization of Maize Wastewater and Its By-Products}

Before and after submerged fermentations with P. aeruginosa NEJ01R in optimized conditions (statistical design), RN and fractions were characterized. The concentration of total solids in the RN 
and three fractions (CL, RE and FI) was determined. Porcelain capsules (pre-dried to constant weight) were used in a drying oven at $100{ }^{\circ} \mathrm{C}$ for $1 \mathrm{~h}$, and their initial weight was measured. One milliliter of the sample was placed and dried at $100{ }^{\circ} \mathrm{C}$ for $1 \mathrm{~h}$ and allowed to cool to room temperature, and the final weight was recorded. The concentration $\left(\mathrm{g} \mathrm{L}^{-1}\right)$ of total solids was determined by the weight difference method. The concentration of insoluble solids was determined using porcelain Gooch crucibles and Whatman No. 1 filter; both materials were pre-dried to constant weight for $1 \mathrm{~h}$ in a drying oven. Subsequently, $2 \mathrm{~mL}$ of each sample was filtered in porcelain Gooch crucibles, and the crucibles with the filter paper were dried in an oven $\left(100{ }^{\circ} \mathrm{C}, 1 \mathrm{~h}\right)$. Finally, their final weight was measured. The concentration of insoluble solids was determined by the weight difference method. The soluble solids were obtained by the difference between the weight of total solids and the weight of insoluble solids. The ashes in the fractions were also determined, and porcelain crucibles were pre-dried to constant weight in a drying oven $\left(100^{\circ} \mathrm{C}, 1 \mathrm{~h}\right)$. Then, $1 \mathrm{~mL}$ of the sample was placed in crucibles until dry on a heating plate $\left(100^{\circ} \mathrm{C}\right)$. The dry crucibles with samples were placed in a muffle $\left(550^{\circ} \mathrm{C}, 2 \mathrm{~h}\right)$. Finally, the final weight was measured. The ash concentration was determined by the weight difference method and reported in $\mathrm{g} \mathrm{L}^{-1}$.

\subsection{Ferulic Acid Determination}

The analysis of ferulic acid was carried out by an H-Class Acquity ultra-performance liquid chromatography (UPLC) system (Waters ${ }^{\circledR}$, Mildford, MA, USA) using a C18 Waters UPLC BEH C18 column $(50 \mathrm{~mm} \times 2.1 \mathrm{~mm}$ i.d., $1.7 \mu \mathrm{m})$. Water/acetonitrile as a mobile phase was at 90:10 ratio, using a flow of $0.3 \mathrm{~mL} \mathrm{~min}{ }^{-1}$, maintaining the temperature of the column at $30{ }^{\circ} \mathrm{C}$, with an injection volume of $5 \mu \mathrm{L}$ and elution times of $5 \mathrm{~min}$. The UPLC system was coupled to the quaternary pump, refrigerated autosampler and an extended wavelength photodiode array detector (PDA detector, Waters ${ }^{\circledR}$, Mildford, MA, USA). In PDA detection, the system was employed by recording a wavelength of $320 \mathrm{~nm}$. The chromatographic data were obtained and processed by the software Empower3 (Waters ${ }^{\circledR}$, Mildford, MA, USA).

\subsection{PYO Identification}

An analysis was performed on a UPLC system with a cooling autosampler, a quaternary solvent manager, an oven for an analytical column, a PDA Detector and an Acquity QDa mass detector (Waters ${ }^{\circledR}$, Mildford, MA, USA). The QDa mass detector is a compact, single, quadrupole mass detector equipped with an electrospray ionization (ESI) interface. A Waters UPLC BEH C18 column $(50 \mathrm{~mm} \times$ $2.1 \mathrm{~mm}$ i.d., $1.7 \mu \mathrm{m}$ ) was used at $30^{\circ} \mathrm{C}$. Water (HPLC grade) with $0.1 \%$ formic acid was used as mobile phase $\mathrm{A}$, and mobile phase $\mathrm{B}$ was acetonitrile. The workflow was $0.3 \mathrm{~mL} \mathrm{~min}^{-1}$, with a mobile phase $\mathrm{A}: \mathrm{B}$ ratio of $95: 5 v / v$. The injection volume was $10 \mu \mathrm{L}$, with the autosampler kept at $15^{\circ} \mathrm{C}$. For mass detection, the QDa detector was operated in an electrospray positive-ion mode and the cone voltage was set at $10 \mathrm{~V}$. The desolvation temperature was set at $600^{\circ} \mathrm{C}$. The Mass Spectrometry (MS) scan mode was used for a full mass spectrum between $\mathrm{m} / \mathrm{z} 100$ and 300, acquired with a sample rate of 5 points/s. In PDA detection, the system was employed by recording a multiwavelength set in the wavelength range of 210-800 nm. PYO (Sigma-Aldrich, St Louis, MO, USA) was used as the standard. All samples and standards were filtered by a $0.2 \mu \mathrm{m}$ nylon membrane. Areas of peaks were determined using the Empower3 chromatography software (Waters ${ }^{\circledR}$, Mildford, MA, USA).

\subsection{Electrochemical Study}

Cyclic voltammetry $(\mathrm{CV})$ was performed at different scan rates on a conventional three-electrode cell employing a glassy carbon electrode as the working electrode, a Pt electrode as the counter electrode and $\mathrm{Ag} / \mathrm{AgCl}$ as the reference electrode $(3 \mathrm{M} \mathrm{NaCl})$. Measurements were carried on a potentiostatic/galvanostatic device (Biologic VSP, Grenoble, France). Ten milliliters of sodium phosphate buffer $(0.2 \mathrm{M}, \mathrm{pH}=7)$ was used as the supporting electrolyte in the presence of PYO $(0.14 \mathrm{mM})$ extracted from $P$. aeruginosa NEJ01R. Prior to each measurement, the solutions were purged 
with highly purified nitrogen for $10 \mathrm{~min}$, and the compensation of the ohmic drop was carried out using electrochemical impedance spectroscopy. The resistance to the solution was measured at a frequency of $100 \mathrm{kHz}$ with a sinus amplitude of $10 \mathrm{mV}$. The potential was established in its open-circuit value. The ohmic drop was set at $85 \%$.

\section{Results and Discussion}

\subsection{Culture Condition Optimization in Defined Medium}

In order to determine the interaction of different variables (factors) with microbial growth and metabolite production by $P$. aeruginosa NEJ01R, a design experiment coupled to surface response methodology was employed. A central composite design also allowed us to evaluate the optimal conditions in the biomass and PYO produced in a defined culture medium (LB broth). At present, there are no studies that report optimization using statistical tools to determine the best combination of factors to obtain high concentrations of PYO in biological processes using LB broth. Table 1 shows the total experiments and results of biomass and PYO obtained.

Table 1. Experimental central composite design matrix; biomass and pyocyanin (PYO) experimental results.

\begin{tabular}{|c|c|c|c|c|c|c|c|}
\hline \multirow{3}{*}{$\begin{array}{l}\text { Unit } \\
1\end{array}$} & \multicolumn{3}{|c|}{ Experimental Code Factors } & \multicolumn{4}{|c|}{ Results } \\
\hline & \multirow{2}{*}{$\begin{array}{c}\text { Temperature } \\
\left(\mathbf{X}_{\mathbf{1}}\right)\end{array}$} & \multirow{2}{*}{$\begin{array}{c}\mathbf{p H} \\
\left(\mathrm{X}_{2}\right) \\
0\end{array}$} & \multirow{2}{*}{$\begin{array}{c}\begin{array}{c}\text { Agitation } \\
\left(\mathrm{X}_{3}\right)\end{array} \\
0\end{array}$} & \multicolumn{2}{|c|}{$\begin{array}{c}\text { Biomass } \\
\mathrm{g} \mathrm{L}^{-1}\end{array}$} & \multicolumn{2}{|c|}{$\begin{array}{c}\text { PYO } \\
\mu \mathrm{g} \mathrm{mL}^{-1}\end{array}$} \\
\hline & & & & 0.368 & 0.380 & 1.5903 & 1.4260 \\
\hline 2 & -1 & -1 & 1 & 0.512 & 0.484 & 0.0001 & 0.0001 \\
\hline 3 & 1 & -1 & -1 & 0.480 & 0.330 & 0.6600 & 0.5800 \\
\hline 4 & 1 & 1 & -1 & 0.318 & 0.278 & 0.4788 & 0.3420 \\
\hline 5 & 0 & 0 & -1.47119 & 0.600 & 0.710 & 2.8200 & 2.7800 \\
\hline 6 & 0 & 0 & 0 & 0.388 & 0.380 & 1.5732 & 1.4312 \\
\hline 7 & 0 & 0 & 0 & 0.368 & 0.366 & 1.6416 & 1.6758 \\
\hline 8 & -1.47119 & 0 & 0 & 0.440 & 0.470 & 0.5814 & 0.4275 \\
\hline 9 & 1 & -1 & 1 & 0.440 & 0.370 & 1.1900 & 1.2800 \\
\hline 10 & 0 & 1.47119 & 0 & 0.036 & 0.020 & 0.0500 & 0.0400 \\
\hline 11 & 1.47119 & 0 & 0 & 0.252 & 0.188 & 0.0342 & 0.0223 \\
\hline 12 & 0 & 0 & 0 & 0.340 & 0.380 & 1.5390 & 1.4483 \\
\hline 13 & 0 & 0 & 0 & 0.358 & 0.346 & 1.5323 & 1.4141 \\
\hline 14 & -1 & 1 & 1 & 0.320 & 0.398 & 1.4706 & 1.5561 \\
\hline 15 & -1 & -1 & -1 & 0.705 & 0.386 & 0.9498 & 1.0602 \\
\hline 16 & 0 & 0 & 1.47119 & 0.974 & 0.484 & 0.6669 & 0.7011 \\
\hline 17 & 1 & 1 & 1 & 0.370 & 0.240 & 0.1300 & 0.2200 \\
\hline 18 & -1 & 1 & -1 & 0.364 & 0.356 & 1.4193 & 1.2996 \\
\hline 19 & 0 & -1.47119 & 0 & 0.380 & 0.342 & 2.3127 & 2.3598 \\
\hline
\end{tabular}

Analysis of results was done considering the variability from experimental factors and total error (Table 2). Experimental conditions evaluated in this work allowed us to have several values of biomass and PYO. In some experiments, the biomass was preferred instead of PYO. Maximum biomass and PYO generated were $0.974 \mathrm{~g} \mathrm{~L}^{-1}$ and $2.82 \mu \mathrm{g} \mathrm{mL} \mathrm{g}^{-1}$, respectively; and minimum values were: biomass $=0.02 \mathrm{~g} \mathrm{~L}^{-1}$ and $\mathrm{PYO}=0.0001 \mu \mathrm{g} \mathrm{mL}-1$. 
Table 2. ANOVA for biomass and PYO generated from the defined culture medium.

\begin{tabular}{ccccc}
\hline \multirow{2}{*}{ Source } & \multicolumn{2}{c}{ Biomass } & \multicolumn{2}{c}{ PYO } \\
\cline { 2 - 5 } & Coefficient & $p$-Value & Coefficient & $p$-Value \\
\hline Constant $\left(\mathrm{X}_{0}\right)$ & 0.3674 & & 1.5832 & \\
Temperature $\left(\mathrm{X}_{1}\right)$ & -0.0390 & 0.0732 & -0.1539 & 0.01757 \\
$\mathrm{pH}\left(\mathrm{X}_{2}\right)$ & -0.0655 & 0.0042 & -0.2053 & 0.0744 \\
Agitation $\left(\mathrm{X}_{3}\right)$ & 0.0227 & 0.2869 & -0.2712 & 0.0210 \\
Temperature:temperature $\left(\mathrm{X}_{1}{ }^{2}\right)$ & -0.0138 & 0.5700 & -0.6030 & 0.0001 \\
Temperature:pH $\left(\mathrm{X}_{1} \mathrm{X}_{2}\right)$ & 0.0413 & 0.1236 & -0.3620 & 0.0138 \\
Temperature:agitation $\left(\mathrm{X}_{1} \mathrm{X}_{3}\right)$ & 0.0336 & 0.2074 & 0.1838 & 0.1919 \\
pH:pH $\left(\mathrm{X}_{2}{ }^{2}\right)$ & -0.0799 & 0.0026 & -0.1760 & 0.1769 \\
pH:agitation $\left(\mathrm{X}_{2} \mathrm{X}_{3}\right)$ & 0.0333 & 0.2107 & 0.0686 & 0.6215 \\
Agitation:agitation $\left(\mathrm{X}_{3}{ }^{2}\right)$ & 0.1499 & 0.000 & 0.0787 & 0.5405 \\
\hline
\end{tabular}

Moreover, the factors' levels were adequately separated to estimate the effects on the responses. Coefficients of regression equation are displayed in Table 3 considering the following equation:

$$
R=\beta_{0}+\beta_{1} X_{1}+\beta_{2} X_{2}+\beta_{3} X_{3}+\beta_{4} X_{1}^{2}+\beta_{5} X_{1} X_{2}+\beta_{6} X_{1} X_{3}+\beta_{7} X_{2}^{2}+\beta_{8} X_{2} X_{3}+\beta_{9} X_{3}^{2}
$$

where $R$ is the estimated value of biomass or PYO and $\beta$ is the polynomial coefficient.

Table 3. Calculated conditions for the maximum biomass and PYO production in the defined culture medium.

\begin{tabular}{ccc}
\hline Response & \multicolumn{2}{c}{$\begin{array}{c}\text { Biomass Calculated, } \mathbf{0 . 7 1} \mathbf{~ g ~ L}^{-\mathbf{1}} \\
\text { PYO Calculated, 2.21 } \boldsymbol{\mu g ~ m L}^{-\mathbf{1}} \\
\text { (Desirability }\end{array}$} \\
\hline Factor & Code & Real Value \\
\hline Temperature $\left({ }^{\circ} \mathrm{C}\right)$ & -0.3220 & 29.6 \\
\hline $\mathrm{pH}$ & -0.5007 & 6.92 \\
\hline Agitation $(\mathrm{rpm})$ & 1.4711 & 223.7 \\
\hline
\end{tabular}

The reduced model was achieved considering the factors with significant effect for biomass and PYO. Pareto charts show only the factors and interactions with effects in the responses (Figure 1). For biomass generation, the $\mathrm{pH}$ and the $\mathrm{pH} / \mathrm{pH}$ interaction had a negative effect, while the interaction agitation/agitation was positive. Moreover, the last interaction had a higher value than $\mathrm{pH}$ and $\mathrm{pH} / \mathrm{pH}$ interaction obtaining a high biomass value, indicating that moderate agitation and low $\mathrm{pH}$ values promoted an increase in the biomass. For the case of PYO, agitation and temperature/temperature and temperature/pH interaction had a negative effect on PYO generation. In the same case for biomass, to have a higher production of $\mathrm{PYO}$, temperature, $\mathrm{pH}$ and agitation values should be at low levels (Table 1). Response surface plots (Figure 2) were constructed from the regression equations for biomass and PYO generation.

Response surface plots (Figure 2) confirmed the principal effect of temperature, $\mathrm{pH}$ and agitation rate. In the case of biomass, maximum values were obtained using low temperature, low $\mathrm{pH}$ and low agitation values. PYO response surfaces had a different behavior because low-medium temperatures also increased PYO generation. $\mathrm{pH}$ values maintained the PYO in a medium value, and the effect of agitation were similar to that of $\mathrm{pH}$. Simultaneous analysis was done to obtain the maximum generation of biomass and PYO considering the temperature, $\mathrm{pH}$ and velocity of agitation. In this case, the desirability as well as factor conditions are shown in Table 3. The maximum biomass and PYO generation calculated from the lineal reduced regression equation are also shown. Simultaneous analysis showed that the factor values obtained the maximum biomass and PYO considering the 
desirability. The best conditions for PYO production obtained by the surface response methodology were used in cultures, reaching PYO $=2.05 \mu \mathrm{g} \mathrm{mL}^{-1}$. These conditions were evaluated to continue the kinetic production of biomass and PYO.

a) Standardized Pareto Chart for Biomass

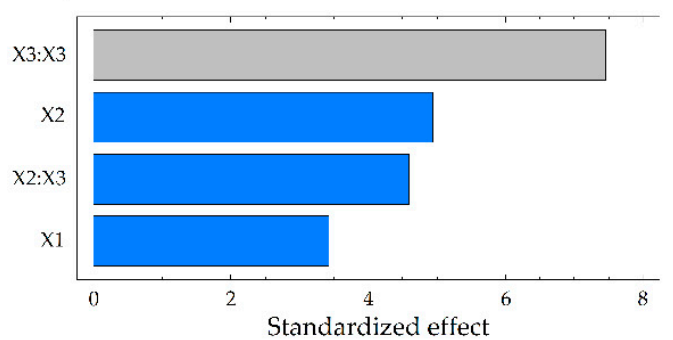

b) Standardized Pareto Chart for PYO

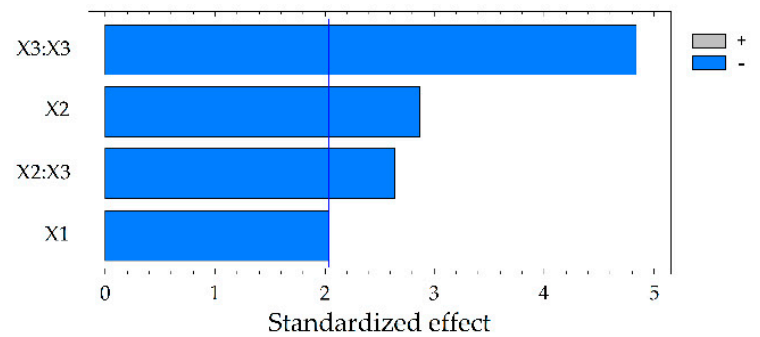

Figure 1. Pareto chart for (a) biomass and (b) pyocyanin (PYO) generation in the defined culture medium. The graphics show only significant effects. $\mathrm{X} 1$, temperature; $\mathrm{X} 2, \mathrm{pH} ; \mathrm{X} 3$, agitation.
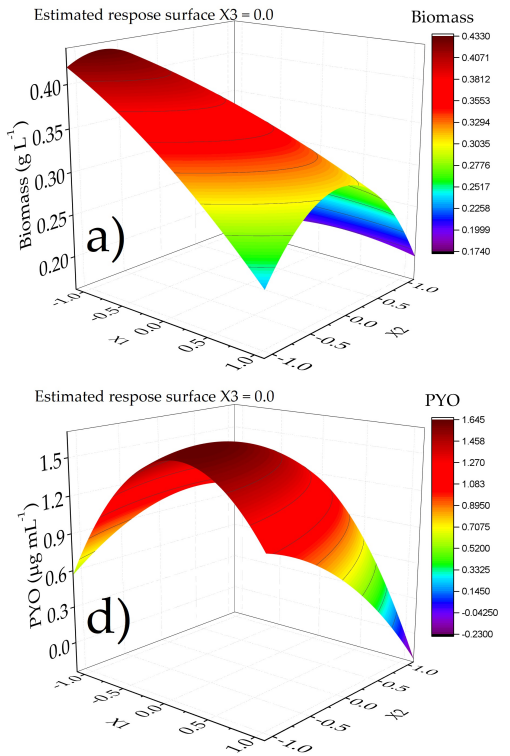
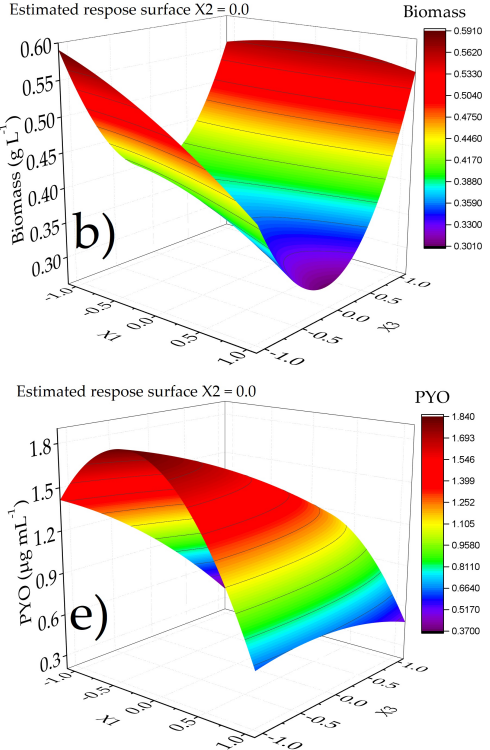
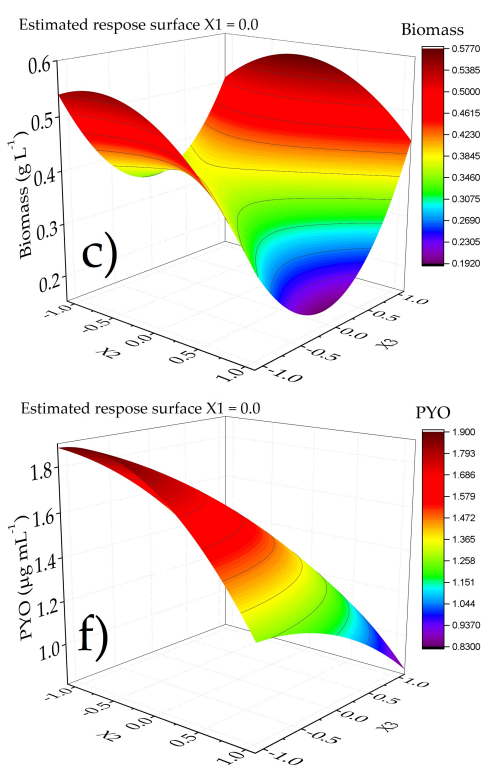

Figure 2. Response surface plots for biomass and PYO production estimated from regression equation in statistical analysis. (a) Interaction between temperature and $\mathrm{pH} ;(\mathbf{b})$ interaction between temperature and agitation rate; (c) interaction between $\mathrm{pH}$ and agitation rate; (d) interaction between temperature and $\mathrm{pH}$; (e) interaction between temperature and agitation rate; (f) interaction between $\mathrm{pH}$ and agitation rate.

\subsection{Microbial Growth Kinetics and PYO Production}

Figure 3a shows the kinetics of microbial growth and PYO production of P. aeruginosa NEJ01R, where the lag phase lasted for $5 \mathrm{~h}$ and subsequently started the exponential phase until $13 \mathrm{~h}$. The stationary phase stayed until $43 \mathrm{~h}$, after which it finally entered the decaying phase. PYO production was not associated with growth because production started at $16 \mathrm{~h}$ once the stationary phase began; then, it did not exhibit the same behavior as bacterial growth. The maximum production of PYO was at $40 \mathrm{~h}$, three hours before starting the death phase. This microbial growth kinetics and PYO production were carried out in a defined LB medium, which is considered as a standard for the incubation period in the culture medium and is able to establish the maximum production time of PYO. Other studies report that the maximum production is after 48 and $72 \mathrm{~h}$ of growth, as is the case for several strains of $P$. aeruginosa isolated from surgical samples, minced meat and infected wounds [36]. The processing time is an important variable to study for the design of processes. In this work, it was possible to obtain a maximum concentration of PYO $\left(3.3 \mu \mathrm{g} \mathrm{mL}^{-1}\right)$ in $40 \mathrm{~h}$ using a defined synthetic medium 
(LB) under optimized conditions in the statistical design. While in other strains of P. aeruginosa, such as KU-BI02, concentrations of $2.560 \mu \mathrm{g} \mathrm{mL} \mathrm{m}^{-1}$ have been produced in $72 \mathrm{~h}$ using King's A medium supplemented with soybean seeds [17]; in strains P. aeruginosa R1 and P. aeruginosa U3, both in King's A medium, $4.5 \mu \mathrm{g} \mathrm{mL} \mathrm{mL}^{-1}$ and $2.4 \mu \mathrm{g} \mathrm{mL}^{-1}$ of PYO were obtained, respectively, at $96 \mathrm{~h}$ of incubation [5].
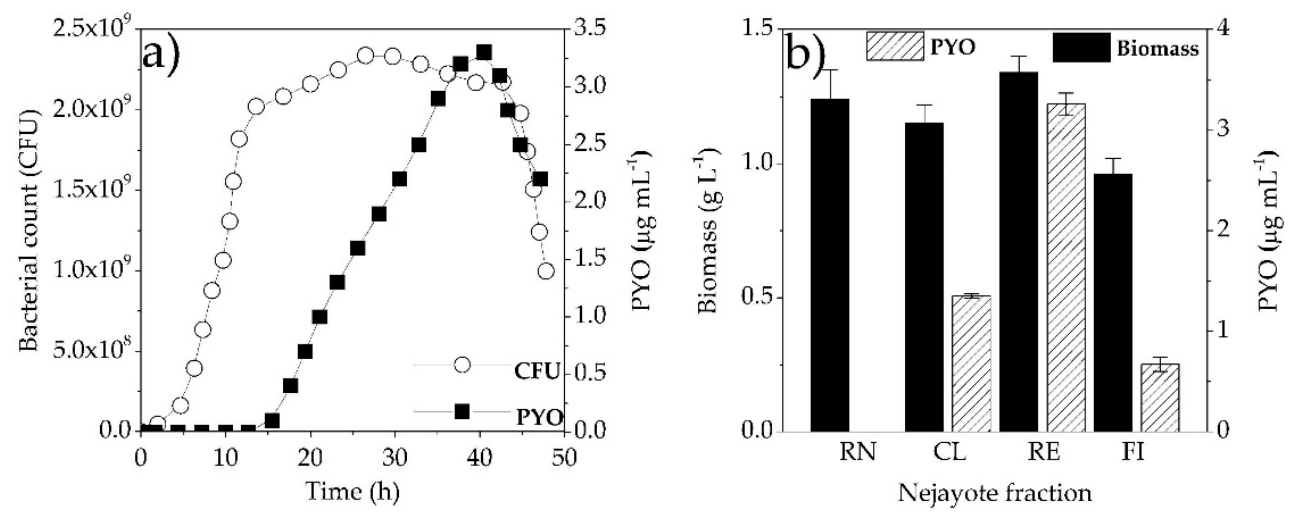

Figure 3. (a) Microbial growth kinetics and PYO production of Pseudomonas aeruginosa NEJ01R under optimized growth conditions; (b) biomass and PYO production of P. aeruginosa NEJ01R using raw nejayote $(\mathrm{RN})$ and fractions (clarified $(\mathrm{CL})$, retentate $(\mathrm{RE})$ and filtered (FI) fractions) under optimized conditions.

\subsection{Maize Wastewater (Nejayote) as a Substrate to PYO Production}

Three fractions of lime-cooked maize wastewater (nejayote) were obtained (CL, RE and FI) in addition to raw nejayote (RN) to evaluate PYO production by P. aeruginosa NEJ01R. Figure $3 \mathrm{~b}$ shows results concerning the samples used separately as the sole carbon source for fermentation of P. aeruginosa NEJ01R and PYO production, using optimal culture conditions established in the defined medium LB. RN substrate was only able to be used as a carbon source by P. aeruginosa NEJ01 because only biomass production was obtained $\left(1.2 \mathrm{~g} \mathrm{~L}^{-1}\right)$. The PYO production was probably hindered due to the alkaline $\mathrm{pH}$ (11) of raw nejayote. These results can be compared with treatments in the experimental design, since in those that presented an alkaline $\mathrm{pH}$ of 11, a minimum PYO production was achieved, such as treatment 10 (Table 1). In the case of the CL fraction, values of biomass production were similar to those obtained in the RN substrate, but with PYO production. Contrary to the RN substrate, $\mathrm{pH}$ was adjusted to 7.2, which had a positive effect on metabolite production considering that the optimum $\mathrm{pH}$ to produce PYO was 6.92, according to the statistical design (Table 3).

The RE fraction had biomass production values higher than that of other fractions. RE and CL fractions were adjusted to $\mathrm{pH}$ 7.2. This condition was favorable for both biomass and PYO production. In the RE fraction, there were molecules larger than $30 \mathrm{kDa}$, which probably favored PYO production. Ultrafiltration (UF) membranes from 3 to $30 \mathrm{kDa}$ concentrate high-molecular-weight components such as proteins, hydrolysates and phenolic fractions according to [37]. Nejayote contains polysaccharides such as feruloylated arabinoxylans, which are non-starchy compounds derived from endosperm cell walls of cereals and formed with a linear - $(1 \rightarrow 4)$-xylopyranose backbone and -L-arabinofuranose residues as side chains on $\mathrm{O} 3$ and $\mathrm{O} 2$ and $\mathrm{O} 3$ [29]. Arabinoxylans can present some arabinose residues ester-linked on (O)-5 to ferulic acid (3-methoxy-4-hydroxycinnamic acid). These compounds display ferulic acid concentrations of $0.6 \mu \mathrm{g} \mathrm{L} \mathrm{L}^{-1}$, as well as an arabinose-to-xylose ratio (A/X) of 0.57-0.65 with a molecular weight of $60 \mathrm{kDa}$ [26]. In this work, the membrane used for the separation of fractions was $30 \mathrm{kDa}$, so it was possible that feruloylated arabinoxylans were in the RE fraction according to [25,27,28]. In that case, $P$. aeruginosa NEJ01R should have an appropriate enzymatic machinery to use this type of polysaccharide as a carbon source, such as polysaccharide-degrading enzymes. Therefore, it is feasible that $P$. aeruginosa NEJ01R produces enzymes to degrade the high volume of polysaccharides present in nejayote RE fraction with a positive effect on PYO production. Different strains of P. aeruginosa 
have demonstrated biosynthesis capacity for effluents of biotechnological processes (with complex composition) such as biodiesel production [16]; raw substrates, such as cottonseed meal, grape seeds, pea pods, taro leaves and olive wastes, hydrolyzed by acids [5]; and others, such as ground corn kernels, ground soybean seeds, potato cooking water, ground watermelon seeds and groundnut [17]. Different concentrations of PYO can be obtained in a defined medium such as nutrient broth and King's A supplemented with $1 \%$ of different raw substrates in submerged fermentations with P. aeruginosa KU-BI02. Ground corn kernel produces $0.3414 \mu \mathrm{g} \mathrm{mL}-1$ of PYO when added to nutrient broth, while adding the same amount to King's A medium yields $1.877 \mu \mathrm{g} \mathrm{mL}^{-1}$ of PYO. Using the same base medium (nutrient broth), the addition of $1 \%$ ground soybean also produces $0.1702 \mu \mathrm{g} \mathrm{mL}^{-1}$, which increases to $1.702 \mu \mathrm{g} \mathrm{mL} \mathrm{L}^{-1}$ when sweet potato cooking water is added. Similarly, minimum concentrations of PYO $\left(0.5106 \mu \mathrm{g} \mathrm{mL} \mathrm{m}^{-1}\right)$ are obtained using King's A medium supplemented with ground watermelon seeds until reaching $2.560 \mu \mathrm{g} \mathrm{mL} \mathrm{m}^{-1}$ of PYO when the same King's A medium is supplemented with ground soybean [17].

On the other hand, the FI fraction displayed a lower production of biomass and PYO, which indicated that its components had a negative effect on its production. This fraction contains low-molecular-weight polysaccharides (molecules smaller than $30 \mathrm{kDa}$ ) and free hydroxycinnamic acids according to $[25,27,28]$. In nejayote, ferulic acid, $p$-coumaric acid and other oligomers have been reported [21,26], as well as antimicrobial capacity. p-Coumaric acid inhibited the growth of Escherichia coli (99.9\%) at $1000 \mu \mathrm{g} \mathrm{mL}-1$, while Staphylococcus aureus and Bacillus cereus were inhibited at $500 \mu \mathrm{g} \mathrm{mL}^{-1}$ [38]. Other reports indicate that $0.1 \mathrm{~g} \mathrm{~L}^{-1}$ of ferulic acid is the minimum inhibitory concentration for E. coli and P. aeruginosa, and $1.1 \mathrm{~g} \mathrm{~L}^{-1}$ and $1.25 \mathrm{~g} \mathrm{~L}^{-1}$ for S. aureus and Listeria monocytogenes, respectively [39]. The highest proportion of hydroxycinnamic acids present in maize wastewater are linked to other molecules such as carbohydrates. However, a significant amount of hydroxycinnamic acid has also been found in free form. The concentration of ferulic acid in nejayote depends on the nixtamalization condition process and corn variety. In nixtamalization processes using different types of maize, ferulic acid concentration has been reported with values of 99.1 for white corn, 96.74 for yellow corn, 88.63 for red corn and $84.95 \mathrm{mg} / 100 \mathrm{~g}$ of dry matter for blue corn [23]. In this work, for the FI fraction, ferulic acid concentration was $2.1 \mathrm{~g} \mathrm{~L}^{-1}$, a higher concentration than that reported previously. The lowest concentration of PYO obtained in the nejayote fraction (FI) was $0.67 \mu \mathrm{g} \mathrm{L}^{-1}$. These results indicated that $P$. aeruginosa NEJ01R strain displayed resistance to the antimicrobial effect of ferulic acid and inhibition of PYO production.

In nixtamalization wastewater fractions, a similar ferulic acid concentration was found, which prevented an antimicrobial effect as shown in Figure $3 b$. The effect of hydroxycinnamic acids on PYO production by P. aeruginosa was reported previously, demonstrating that $4 \mathrm{mM}$ of ferulic acid can inhibit about $20 \%$ of PYO production [40]. In another study, it was shown that phenolic compounds, such as methyl gallate, have a negative effect on PYO production related to quorum sensing system and other molecules that inhibited the formation of biofilm, motility, proteolytic, elastase or rhamnolipid production in P. aeruginosa PAO1 [41]. In our results, after treatment with P. aeruginosa NEJ01R, the initial concentration of ferulic acid decreased by $10 \%$ for CL and FI fractions. In the RE fraction and RN substrate, values decreased to $15 \%$ and $20 \%$, respectively, suggesting that P. aeruginosa NEJ01R can use molecules of ferulic acid as a carbon source.

Furthermore, during the cooking process of corn, to obtain nixtamal, $0.5-2 \%$ of calcium hydroxide is added, so this compound may be present in the wastewater obtained. It has been reported that the concentration of this compound in nejayote can be up to $1526.21 \mathrm{mg} \mathrm{L}^{-1}$ [22]. The calcium hydroxide residues present in nixtamalization wastewater can have a negative impact on low PYO production using the FI fraction since it is likely that a high concentration of calcium was present. It was also demonstrated that a fraction with a concentration of $3155.3 \pm 5.24 \mathrm{mg} \mathrm{L}^{-1}$ of calcium was obtained using clarified nejayote filtered by a $1 \mathrm{kDa}$ membrane [42]. Therefore, according to our results, the FI fraction may have had a high calcium concentration that interfered with PYO production by P. aeruginosa NEJ01R. In a study about the effect of calcium chloride concentration on PYO production by P. aeruginosa 
NRRL B-771 and a PaJC mutant, it was demonstrated that $50 \mathrm{mM}$ of calcium chloride in the presence of $1 \%$ sucrose produced a PYO concentration of $3.53 \mu \mathrm{g} \mathrm{mL}^{-1}$ and $3.06 \mu \mathrm{g} \mathrm{mL}^{-1}$ for P. aeruginosa NRRL B-771 and the PaJC mutant, respectively. When the calcium chloride concentration was increased to $250 \mathrm{mM}$, the PYO production decreased to $1.66 \mu \mathrm{g} \mathrm{mL}^{-1}$ and $2.51 \mu \mathrm{g} \mathrm{mL} \mathrm{L}^{-1}$ for P. aeruginosa NRRL B-771 and the PaJC mutant, respectively [43]. This suggests that the concentration of calcium in the culture medium has a negative effect on the PYO production of $P$. aeruginosa NEJ01R. If we consider the membrane size used to obtain the fractions RE and FI, it is likely that a higher concentration of calcium accumulates in the FI fraction, and this would have a negative effect on PYO production related to lower concentration in the FI fraction compared with the RE fraction. Then, the ultrafiltration process utilized showed an efficient system to fractionate nixtamalization wastewater that is feasible in PYO production by $P$. aeruginosa NEJ01R in order to valorize maize by-products.

\subsection{Characterization of Maize Wastewater Fractions}

Figure 4 shows values of parameters evaluated for characterization of nejayote fractions before and after the treatment. The results indicated that total solid (TS) content in the RE fraction increased due to ultrafiltration (UF) treatment; it was possible to obtain a fraction concentrate with $34 \%$ more solids than that contained in the RN substrate. The composition of nejayote fractions separated by UF $(100 \mathrm{kDa})$ is mainly ferulated arabinoxylans, which are phenolic compounds linked to long-chain carbohydrates $[25,27]$. The concentration of solids decreased by $20 \%$ after treatment with P. aeruginosa NEJ01R, with the highest percentage of total solids being removed, as well as the CL fraction, in which $20 \%$ of TS was also removed. Similarly, for soluble solids (SS) in the treatment of RE fraction, a higher concentration of SS (20\%) was removed, and for the CL fraction, $18 \%$ was removed. The highest percentage of removal of insoluble solids (IS) was obtained in RN (50\%). The crude nejayote did not receive any previous treatment as the fractions that displayed a higher initial content of IS. For CL and RE fractions, the removal percentages of IS were $22 \%$ and $29 \%$, respectively.
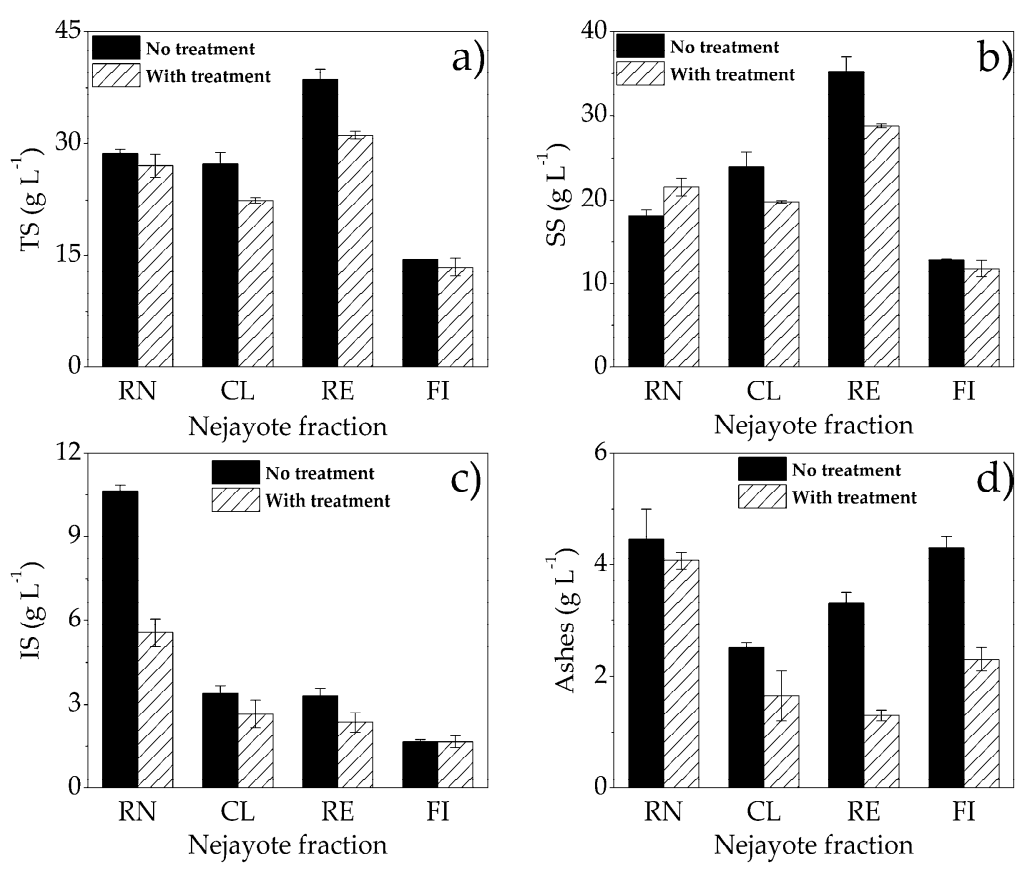

Figure 4. Determination of (a) total solids (ST), (b) soluble solids (SS), (c) insoluble solids (IS) and (d) ashes in nixtamalization wastewater crude (RN) and fractions (CL, RE and FI).

The FI fraction did not present IS removal, besides being the fraction that initially displayed the lowest IS concentration and was not used as a carbon source by P. aeruginosa NEJ01R. However, the FI fraction presented an ash removal of $45 \%$, and the largest ash removal was in the RE fraction 
with $60 \%$, followed by the CL fraction with $34 \%$ ash removal. These results showed that treatment with $P$. aeruginosa NEJ01R achieved a greater removal of solids in the RE fraction, which indicated that the concentration of solids favored the consumption of this as a carbon source by the strain used (P. aeruginosa NEJ01R). On the other hand, the fraction with the lowest solid removal was the FI fraction, which was also related to lower production of biomass and PYO, demonstrating that the type of molecules present in this fraction could have a negative effect, mainly in PYO production.

\subsection{PYO Identification}

The ultra-performance liquid chromatography system (UPLC system) was employed to analyze the sample extracted and compare it with a commercial standard (Sigma-Aldrich, St Louis, MO, USA). The sample extracted from the supernatant of the culture using P. aeruginosa NEJ01R showed two maximum peaks of 278 and $387 \mathrm{~nm}$, similar to the standard commercial product (Figure S1, Supplementary Material). The UPLC chromatogram showed a single peak with a retention time of 1.45 min for PYO standard, which was comparable to that of the extracted sample, which suggested that it was the same molecule. On the other hand, the maximum at $278 \mathrm{~nm}$ of PYO was also reported for a culture of $P$. aeruginos $a \mathrm{TBH} 2$, an extracted sample obtained with chloroform and acidified with $1 \mathrm{M}$ $\mathrm{HCl}$, and in the same way for PYO extracted from cultures of P. aeruginosa N11, P. aeruginosa D23 and a $P$. aeruginosa clinical isolate [3,44]. Figure S2 (Supplementary Material) displays the mass spectra of extract sample and standard PYO, giving a result of $m / z 211(\mathrm{M}+\mathrm{H})$, which coincides with PYO mass of $210 \mathrm{~g} \mathrm{~mol}^{-1}$. This result corresponds with that reported for a culture sample extract of P. aeruginosa BRp3 strain [45]. Our results demonstrated that the molecule extracted from the culture of P. aeruginosa NEJ01R was PYO.

\subsection{Electrochemical Analysis of PYO}

The redox behavior of PYO was analyzed with cyclic voltammetry. Figure 5a shows the electrochemical response of a PYO solution $(0.14 \mathrm{mM})$ in the presence of $0.2 \mathrm{M}$ phosphate buffer solution at $\mathrm{pH}$ 7. The analysis indicated a reduction process $I_{c}$ with a peak potential $E_{p c}$ of $-0.269 \mathrm{~V} v \mathrm{vs}$. $\mathrm{Ag} \mid \mathrm{AgCl} 3 \mathrm{M} \mathrm{NaCl}$ value at $100 \mathrm{mV} \mathrm{s}^{-1}$. In the reversal scan, a reduction process $I_{a}$ was observed with a peak potential $E_{p a}$ of $-0.234 \mathrm{~V}$ vs. $\mathrm{Ag} \mid \mathrm{AgCl} 3 \mathrm{M} \mathrm{NaCl}$ at the same scan rate.

The redox behavior of PYO was studied at different scanning rates. A normalization current analysis was carried out, coming from the following equation:

$$
\frac{i}{n F A C_{O}^{*} D_{O}^{1 / 2}\left(\frac{n F}{R T}\right)^{1 / 2} v^{1 / 2}}=\pi^{1 / 2} x(\sigma t)
$$

where $n$ is the total number of electrons in the redox reaction, $D_{o}^{1 / 2}$ is the PYO diffusion coefficient, $A$ is the electroactive area, $C_{o}$ (PYO concentration) values are constants and $\pi^{1 / 2} \chi(\sigma t)$ is a dimensionless number.

This analysis suggested that the cathodic signal $I_{\mathcal{C}}$ did not have diffusional complications or coupled chemical reactions (Figure 5a). On the other hand, for signal $I_{a}$, the normalization of current values increased with $v^{1 / 2}$. The anodic peak potential $E_{p a}$ varied significantly as the scan rate increased with shifts toward positive values. On the other hand, minimal changes in $E_{p c}$ values were observed when $v^{1 / 2}$ was increased. This behavior suggested a reversible redox behavior with a possible adsorption for $I_{a}$. To confirm this idea, an analysis of the peak current $i_{p}$ as a function of $v^{1 / 2}$ was also performed. According to the following equation (Randles Sevcik) [46], the value of $i_{p}$ must present a linear relationship with $v^{1 / 2}$.

$$
i_{p}=\left(2.69 \times 10^{5}\right) n^{3 / 2} A D_{O}^{1 / 2} C_{O}^{*} v^{1 / 2}
$$



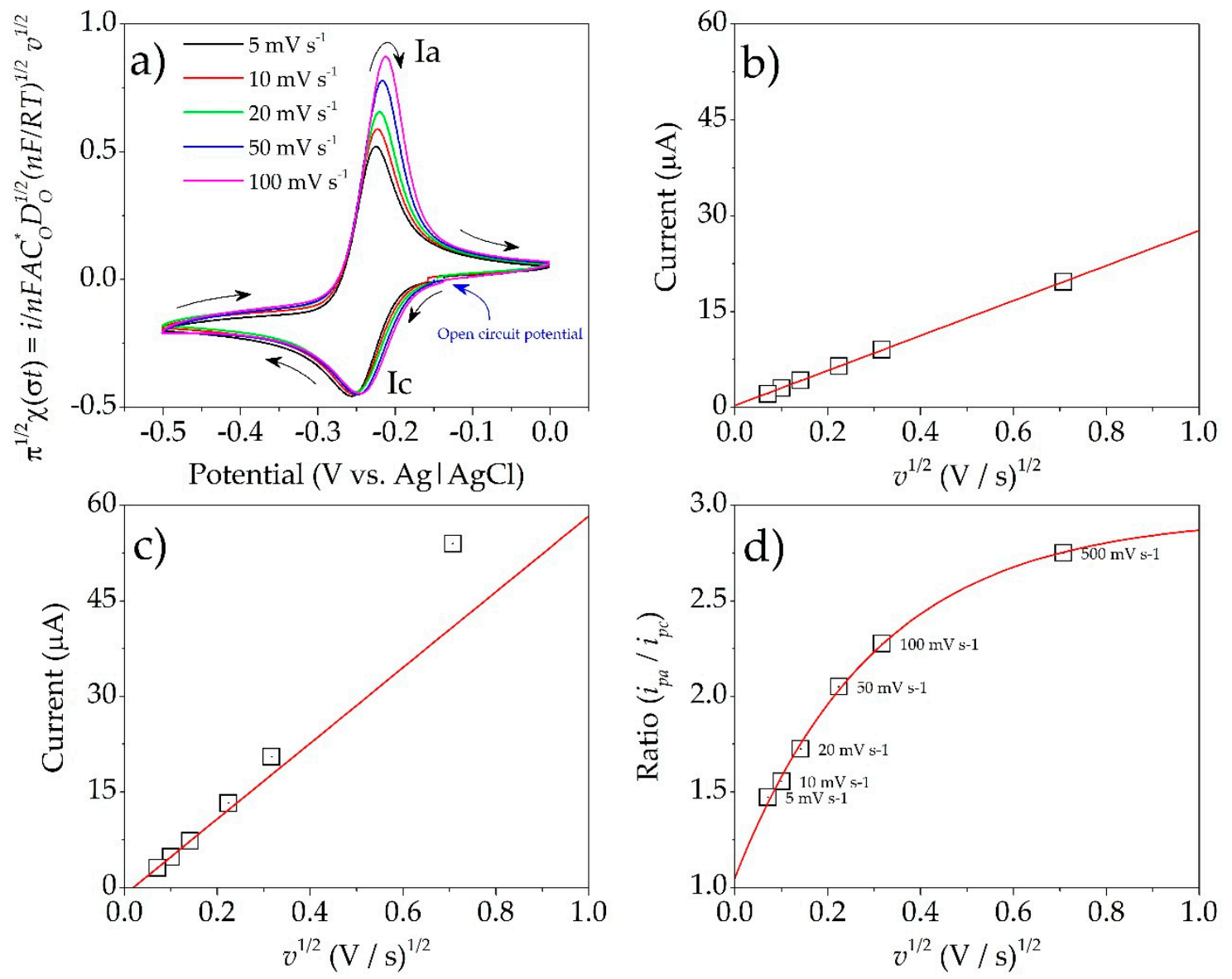

Figure 5. (a) Cyclic voltammetry of PYO $(0.14 \mathrm{M})$ in current normalized at different scan rates $(v)$.

(b) $i_{p c}$ values for PYO $(0.14 \mathrm{M})$ as a function of $v^{1 / 2}$. (c) $i_{p a}$ values for PYO $(0.14 \mathrm{M})$ as a function of $v^{1 / 2}$.

(d) $i_{p a} / i_{p c}$ values of PYO $(0.2 \mathrm{mM})$ as function of $v^{1 / 2}$.

Figure $5 \mathrm{~b}$ presents the linear behavior of $i_{p c}$ with respect to $v^{1 / 2}$, indicating that the electrochemical process Ic of PYO was controlled by diffusion. A change in linearity of $i_{p a}$ vs $v^{1 / 2}$ was observed at high scan rates (Figure $5 c$ ). Hence, the ratio $i_{p a} / i_{p c}$ at different scan rates was evaluated (Figure $5 \mathrm{~d}$ ). The behavior confirmed that the reversal oxidation process $I_{a}$ was controlled by diffusion, with adsorption of PYO significantly reduced over the electrode surface $[10,47]$. Finally, considering low scan rates, where the adsorption process was not presented, a value of $\left|\Delta E_{p}\right|=0.035 \mathrm{~V}$ was calculated, which indicated a two-electron transfer, according to Equation (6). A value of $E_{1 / 2}=-0.251 \mathrm{~V}$ vs. $\mathrm{Ag} \mid \mathrm{AgCl} 3 \mathrm{M} \mathrm{NaCl}$, related to the redox pair of $\mathrm{PYO}$, was calculated according to Equation (7) [48,49]. Different applications of PYO have been described, in agriculture, medicine and the textile industry. However, the observation in two areas of application for this molecule is limited, namely in the extracellular transport of electrons in bioelectrochemical systems, specifically as biosensors, and in microbial electrochemical technologies. The phenomenon observed at high scanning speeds due to complications in the electrode related to absorption processes could be analyzed in future research to advance the application in the mentioned areas.

$$
\begin{gathered}
\left|E_{p a}-E_{p c}\right|=\frac{59 \mathrm{mV}}{n} \\
\frac{E_{p a}+E_{p c}}{2}=E_{1 / 2}
\end{gathered}
$$




\section{Conclusions}

In this study, a coupled methodology of design of experiments and response surfaces was used to determine the optimal process conditions for obtaining PYO in submerged fermentation by P. aeruginosa NEJ01R. These conditions $\left(29.6^{\circ} \mathrm{C}, 223.7 \mathrm{rpm}, \mathrm{pH}\right.$ 6.92) were evaluated experimentally, in LB medium, reaching values $\left(2.05 \mu \mathrm{g} \mathrm{mL}^{-1}\right)$ close to those predicted statistically $\left(2.21 \mu \mathrm{g} \mathrm{mL}^{-1}\right)$. We demonstrated that the by-product of the maize industry can be a culture medium, without supplementation, that supports the production of PYO, only in its pretreated fractions and separated by an ultrafiltration membrane. The highest PYO concentration $\left(3.25 \mu \mathrm{g} \mathrm{mL}^{-1}\right)$ was obtained in the RE fraction at $48 \mathrm{~h}$. Furthermore, the high concentration of ferulic acid $\left(2.1 \mathrm{~g} \mathrm{~L}^{-1}\right)$ in the FI fraction did not have a negative effect on the growth of $P$. aeruginosa, which is related to resistance to its antimicrobial effect, although it did show a negative effect on the production of PYO. This is the first work that reports the use of wastewater as the only carbon source to synthesize PYO by a native strain of P. aeruginosa (NEJ01R). The molecule obtained showed redox behavior without diffusion complications at low scan rates.

Response surface plots indicated the relevance of factors with a significant effect for biomass and PYO production, indicating a positive effect using values in the low level (temperature, $21.5^{\circ} \mathrm{C}$; $\mathrm{pH}$, 5; agitation, $76 \mathrm{rpm}$ ) for higher production in both responses. Optimized variables for PYO production in alkaline residual liquid of the maize industry and a detailed characterization establishing the composition of nejayote fractions and compounds that are involved in the metabolic induction of PYO are in progress.

Supplementary Materials: The following are available online at http://www.mdpi.com/2076-2607/8/10/1559/s1, Table S1: Experimental design matrix for biomass and PYO production in the defined culture medium, Figure S1: (a) Chromatograms and absorption spectra of PYO standard and (b) PYO extracted from Pseudomonas aeruginosa NEJ01R culture supernatant, Figure S2: (a) Mass spectra of PYO standard and (b) PYO extracted from Pseudomonas aeruginosa NEJ01R culture supernatant.

Author Contributions: Conceptualization, F.J.B.-V. and Y.R.-V.; investigation, M.L.F.-M. and J.A.P.-G.; formal analysis, F.E.-A.; validation, F.E.-A. and L.A.O.-F.; visualization, J.A.P.-G. and Y.R.-V.; writing-original draft preparation, F.J.B.-V. and Y.R.-V.; writing-review and editing, L.A.O.-F. and Y.R.-V.; funding acquisition, Y.R.-V. All authors have read and agreed to the published version of the manuscript.

Funding: This research was funded by Consejo Nacional de Ciencia y Tecnología (CONACYT), México (project 255468 Conacyt-Infraestructura, project 246052 Conacyt-SENER-Sustentabilidad Energética and project 258159 Conacy-SEP-Ciencia Básica).

Acknowledgments: F.J.B.-V., J.A.P.-G. and M.L.F.-M. are grateful to CONACYT for postdoctoral and doctoral scholarship support, and the authors are grateful to H.G. Cortes Cano for technical assistance and J. Peña-Castro for molecular biology assistance.

Conflicts of Interest: The authors declare no conflict of interest.

\section{References}

1. Samrot, A.V.; Rio, J.A.; Kumar, S.S.; Samanvitha, S.K. Bioprospecting studies of pigmenting Pseudomonas aeruginosa SU-1, Microvirga aerilata SU14 and Bacillus megaterium SU15 isolated from garden soil. Biocatal. Agric. Biotechnol. 2017, 11, 330-337. [CrossRef]

2. Yong, X.Y.; Yan, Z.Y.; Shen, H.B.; Zhou, J.; Wu, X.Y.; Zhang, L.J.; Zheng, T.; Jiang, M.; Wei, P.; Jia, H.H.; et al. An integrated aerobic-anaerobic strategy for performance enhancement of Pseudomonas aeruginosa-inoculated microbial fuel cell. Bioresour. Technol. 2017, 241, 1191-1196. [CrossRef] [PubMed]

3. Narenkumar, J.; Sathishkumar, K.; Sarankumar, R.K.; Murugan, K.; Rajasekar, A. An anticorrosive study on potential bioactive compound produced by Pseudomonas aeruginosa TBH2 against the biocorrosive bacterial biofilm on copper metal. J. Mol. Liq. 2017, 243, 706-713. [CrossRef]

4. Stancu, M.M. Production of some extracellular metabolites by a solvent-tolerant Pseudomonas aeruginosa strain. Waste Biomass Valor. 2018, 9, 1747-1755. [CrossRef]

5. El-Fouly, M.Z.; Sharaf, A.M.; Shahin, A.A.M.; El-Bialy, H.A.; Omara, A.M.A. Biosynthesis of pyocyanin pigment by Pseudomonas aeruginosa. J. Radiat. Res. Appl. Sci. 2015, 8, 36-48. [CrossRef] 
6. Chatterjee, M.; D’Morris, S.; Vinod, P.; Warrier, S.; Vasudevan, A.K.; Vanuopadath, M.; Nair, S.S.; Paul-Prasanth, B.; Mohan, C.G.; Biswas, R. Mechanistic understanding of Phenyllactic acid mediated inhibition of quorum sensing and biofilm development in Pseudomonas aeruginosa. Appl. Microbiol. Biotechnol. 2017, 101, 8223-8236. [CrossRef]

7. Kang, H.; Gan, J.; Zhao, J.; Kong, W.; Zhang, J.; Zhu, M.; Li, F.; Song, Y.; Qin, J.; Liang, H. Crystal structure of Pseudomonas aeruginosa RsaL bound to promoter DNA reaffirms its role as a global regulator involved in quorum-sensing. Nucleic Acids Res. 2017, 45, 699-710. [CrossRef]

8. Patil, S.; Nikam, M.; Patil, H.; Anokhina, T.; Kochetkov, V.; Chaudhari, A. Bioactive pigment production by Pseudomonas spp. MCC 3145: Statistical media optimization, biochemical characterization, fungicidal and DNA intercalation-based cytostatic activity. Process. Biochem. 2017, 58, 298-305. [CrossRef]

9. Price-Whelan, A.; Dietrich, L.; Newman, D. Rethinking 'secondary' metabolism: Physiological roles for phenazine antibiotics. Nat. Chem. Biol. 2006, 2, 71-78. [CrossRef]

10. Oziat, J.; Gougis, M.; Malliaras, G.G.; Mailley, P. Electrochemical characterizations of four main redox-metabolites of Pseudomonas aeruginosa. Electroanalysis 2017, 29, 1332-1340. [CrossRef]

11. Qiao, Y.; Qiao, Y.J.; Zou, L.; Ma, C.X.; Liu, J.H. Real-time monitoring of phenazines excretion in Pseudomonas aeruginosa microbial fuel cell anode using cavity microelectrodes. Bioresour. Technol. 2015, 198, 1-6. [CrossRef] [PubMed]

12. Cayman Chemical Co. Home Page. Available online: https://www.caymanchem.com/product/10009594/ pyocyanin (accessed on 4 September 2020).

13. Focus Biomolecules Home Page. Available online: https://focusbiomolecules.com/pyocyanin-ros-generator/ (accessed on 4 September 2020).

14. Santa Cruz Biotechnology Home Page. Available online: https://www.scbt.com/p/pyocyanin-85-66-5 (accessed on 4 September 2020).

15. Sigma-Aldrich Home Page. Available online: https://www.sigmaaldrich.com/catalog/product/sigma/p0046? lang=es\&region=MX (accessed on 4 September 2020).

16. Bacame-Valenzuela, F.J.; Pérez-Garcia, J.A.; Castañeda-Zaldívar, F.; Reyes-Vidal, Y. Pyocyanin biosynthesis by Pseudomonas aeruginosa using a biodiesel byproduct. Mex. J. Biotechnol. 2020, 5, 1-16. [CrossRef]

17. DeBritto, S.; Gajbar, T.D.; Satapute, P.; Sundaram, L.; Lakshmikantha, R.Y.; Jogaiah, S.; Ito, S. Isolation and characterization of nutrient dependent pyocyanin from Pseudomonas aeruginosa and its dye and agrochemical properties. Sci. Rep. 2020, 10, 1542. [CrossRef] [PubMed]

18. Valderrama-Bravo, C.; Domínguez-Pacheco, F.; Hernández-Aguilar, C.; Flores-Saldaña, N.; Villagran-Ortiz, P.; Pérez-Reyes, C.; Sánchez-Hernández, G.; Oaxaca-Luna, A. Effect of nixtamalized maize with lime water (nejayote) on rheological and microbiological properties of masa. J. Food Process. Preserv. 2017, 41, e12748. [CrossRef]

19. Villada, J.A.; Sánchez-Sinencio, F.; Zelaya-Ángel, O.; Gutiérrez-Cortes, E.; Rodríguez-García, M.E. Study of the morphological, structural, thermal, and pasting corn transformation during the traditional nixtamalization process: From corn to tortilla. J. Food Eng. 2017, 212, 242-251. [CrossRef]

20. Rojas-García, C.; García-Lara, S.; Serna-Saldivar, S.O.; Gutiérrez-Uribe, J.A. Chemopreventive effects of free and bound phenolics associated to steep waters (Nejayote) obtained after nixtamalization of different maize types. Plant. Foods Hum. Nutr. 2012, 67, 94-99. [CrossRef]

21. Argun, M.S.; Argun, M.E. Treatment and alternative usage possibilities of a special wastewater: Nejayote. J. Food Process. Eng. 2017, 48, e12609. [CrossRef]

22. Castro-Muñoz, R.; Fila, V.; Durán-Páramo, E. A review of the primary by-product (Nejayote) of the nixtamalization during maize processing: Potential reuses. Waste Biomass Valor. 2019, 10, 13-22. [CrossRef]

23. Gutiérrez-Uribe, J.A.; Rojas-García, C.; García-Lara, S.; Serna-Saldivar, S.O. Phytochemical analysis of wastewater (nejayote) obtained after lime-cooking of different types of maize kernels processed into masa for tortillas. J. Cereal Sci. 2010, 52, 410-416. [CrossRef]

24. López-Pacheco, I.Y.; Carrillo-Nieves, D.; Salinas-Salazar, C.; Silva-Núñez, A.; Arévalo-Gallegos, A.; Barceló, D.; Afewerki, S.; Izbal, H.M.N.; Parra-Saldívar, R. Combination of nejayote and swine wastewater as a medium for Arthrospira maxima and Chlorella vulgaris production and wastewater treatment. Sci. Total Environ. 2019, 676, 356-367. [CrossRef] 
25. Asaff-Torres, A.J.; Reyes-Vidal, M.Y. Un Método y un Sistema para el Tratamiento Integral de Aguas Residuales de una Industria del Maíz. WO/2014/119990. 2014. Available online: https:/patentscope.wipo. int/search/es/detail.jsf?docId=WO2014119990 (accessed on 28 September 2020).

26. Ayala-Soto, F.; Serna-Saldívar, S.O.; García-Lara, S.; Pérez-Carrillo, E. Hydroxycinnamic acids, sugar composition and antioxidant capacity of arabinoxylans extracted from different maize fiber sources. Food Hydrocoll. 2014, 35, 471-475. [CrossRef]

27. Castro-Muñoz, R.; Cerón-Montes, G.I.; Barragán-Huerta, B.E.; Yáñez-Fernández, J. Recovery of carbohydrates from nixtamalization wastewaters (Nejayote) by ultrafiltration. Rev. Mex. Ing. Quim. 2015, 14, 735-744.

28. Castro-Muñoz, R.; Yáñez-Fernández, J. Valorization of nixtamalization wastewaters by integrated membrane process. Food Bioprod. Process. 2015, 95, 7-18. [CrossRef]

29. Niño-Medina, G.; Carvajal-Millán, E.; Lizardi, J.; Rascon-Chu, A.; Marquez-Escalante, J.A.; Gardea, A.; Martinez-López, A.L.; Guerrero, V. Maize processing waste water arabinoxylans: Gelling capability and cross-linking content. Food Chem. 2009, 115, 1286-1290. [CrossRef]

30. Rocha-Pizaña, M.R.; Chen, W.N.; Lee, J.J.L.; Bultimea-Cantúa, N.E.; González-Nimi, E.; Gutierrez-Uribe, J.A. Production of a potential collagenolytic protease by nejayote fermentation with Aspergillus oryzae. Int. J. Food Sci. Technol. 2020, 55, 3289-3296. [CrossRef]

31. Ramírez-Romero, G.; Reyes-Velazquez, M.; Cruz-Guerrero, A. Study of nejayote as culture medium for probiotics and production of bacteriocins. Rev. Mex. Ing. Quim. 2013, 12, 463-471.

32. Sanchez-Gonzalez, M.; Blanco-Gamez, A.; Escalante, A.; Valladares, A.G.; Olvera, C.; Parra, R. Isolation and characterization of new facultative alkaliphilic Bacillus flexus strains from maize processing waste water (nejayote). Lett. Appl. Microbiol. 2011, 52, 413-419. [CrossRef]

33. Baqueiro-Peña, I.; Contreras-Jácquez, V.; Kirchmayr, M.R.; Mateos-Díaz, J.C.; Valenzuela-Soto, E.M.; Asaff-Torres, A. Isolation and characterization of a new ferulic-acid-biotransforming Bacillus megaterium from maize alkaline wastewater (nejayote). Curr. Microbiol. 2019, 76, 1215-1224. [CrossRef]

34. García-Depraect, O.; Gómez-Romero, J.; León-Becerril, E.; López-López, A. A novel biohydrogen production process: Co-digestion of vinasse and nejayote as complex raw substrates using a robust inoculum. Int. J. Hydrog. Energy. 2017, 42, 5820-5831. [CrossRef]

35. Wilson, K. Preparation of genomic DNA from bacteria. Curr. Protoc. Mol. Biol. 2001, 56, 2-4. [CrossRef]

36. El-Shouny, W.A.; Al-Baidani, A.R.H.; Hamza, W.T. Antimicrobial activity of pyocyanin produced by Pseudomonas aeruginosa isolated from surgical wound-infections. Intl. J. Pharm. Med. Sci. 2011, 1, 1-7.

37. Castro-Muñoz, R.; Barragán-Huerta, B.E.; Fila, V.; Denis, P.C.; Ruby-Figueroa, R. Current role of membrane technology: From the treatment of agro-industrial by-products up to the valorization of valuable compounds. Waste Biomass Valor. 2018, 9, 513-529. [CrossRef]

38. Herald, P.J.; Davidson, P.M. Antibacterial activity of selected hydroxycinnamic acids. J. Food Sci. 1983, 48, 1378-1379. [CrossRef]

39. Borges, A.; Ferreira, C.; Saavedra, M.J.; Simões, M. Antibacterial activity and mode of action of ferulic and gallic acids against pathogenic bacteria. Microb. Drug Resist. 2013, 19, 256-265. [CrossRef] [PubMed]

40. Ugurlu, A.; Yagci, A.K.; Ulusoy, S.; Aksu, B.; Bosgelmez-Tinaz, G. Phenolic compounds affect production of pyocyanin, swarming motility and biofilm formation of Pseudomonas aeruginosa. Asian Pac. J. Trop. Biomed. 2016, 6, 698-701. [CrossRef]

41. Hossain, M.A.; Lee, S.J.; Park, N.H.; Mechesso, A.F.; Birhanu, B.T.; Kang, J.; Reza, A.; Suh, J.W.; Park, S.C. Impact of phenolic compounds in the acyl homoserine lactone-mediate quorum sensing regulatory pathways. Sci. Rep. 2017, 7, 10618. [CrossRef]

42. Castro-Muñoz, R.; Barragán-Huerta, B.E.; Yáñez-Fernández, J. The use of nixtamalization waste waters clarified by ultrafiltration for production of a fraction rich in phenolic compounds. Waste Biomass Valor. 2016, 7, 1167-1176. [CrossRef]

43. Özcan, D.; Kahraman, H. Pyocyanin production in the presence of calcium ion in Pseudomonas aeruginosa and recombinant bacteria. Turkish J. Sci. Technol. 2015, 10, 13-19.

44. Kerr, J.R.; Taylor, G.W.; Rutman, A.; HØiby, N.; Cole, P.J.; Wilson, R. Pseudomonas aeruginosa pyocyanin and 1-hydroxyphenazine inhibit fungal growth. J. Clin. Pathol. 1999, 52, 385-387. [CrossRef]

45. Yasmin, S.; Hafeez, F.Y.; Mirza, M.S.; Rasul, M.; Arshad, H.M.I.; Zubair, M.; Iqbal, M. Biocontrol of bacterial leaf blight of rice and profiling of secondary metabolites produced by rhizospheric Pseudomonas aeruginosa BRp3. Front. Microbiol. 2017, 8, 1895. [CrossRef] 
46. Bard, A.J.; Faulkner, L.R. Electrochemical Methods: Fundamentals and Applications, 2nd ed.; Harris, D., Swain, E., Eds.; John Wiley \& Sons, Inc.: New York, NY, USA, 2000.

47. Wopschall, R.H.; Shain, I. Effects of adsorption of electroactive species in stationary electrode polarography. Anal. Chem. 1967, 39, 1514-1527. [CrossRef]

48. Friedheim, E.; Michaelis, L. Potentiometric study of piocyanine. J. Biol. Chem. 1931, 91, 355-368.

49. Wang, Y.; Newman, D.K. Redox reactions of phenazine antibiotics with ferric (hydr)oxides and molecular oxygen. Environ. Sci. Technol. 2008, 42, 2380-2386. [CrossRef] [PubMed] 